\title{
Translation of the Frailty Paradigm from Older Adults to Children with Cardiac Disease
}

\author{
Chaitanya Panchangam ${ }^{1,4}$ (D) David A. White ${ }^{2,3} \cdot$ Suma Goudar $^{2,3} \cdot$ Brian Birnbaum $^{2,3} \cdot$ Lindsey Malloy-Walton ${ }^{2,3}$. \\ Jami Gross-Toalson ${ }^{2} \cdot$ Kimberly J. Reid $^{2}$. Girish Shirali ${ }^{2,3} \cdot$ Anitha Parthiban $^{2,3}$
}

Received: 21 October 2019 / Accepted: 23 April 2020 / Published online: 6 May 2020

(c) Springer Science+Business Media, LLC, part of Springer Nature 2020

\begin{abstract}
Children and adolescents with cardiac disease (CCD) have significant morbidity and lower quality of life. However, there are no broadly applicable tools similar to the frailty score as described in the elderly, to define functional phenotype in terms of physical capability and psychosocial wellbeing in CCD. The purpose of this study is to investigate the domains of the frailty in CCD. We prospectively recruited CCD (8-17.5 years old, $70 \%$ single ventricle, $27 \%$ heart failure, $12 \%$ pulmonary hypertension; NYHA classes I, II and III) and age and gender matched healthy controls (total $n=56$; CCD $n=34$, controls $n=22$; age $12.6 \pm 2.6$ years; $39.3 \%$ female). We measured the five domains of frailty: slowness, weakness, exhaustion, body composition and physical activity using developmentally appropriate methods. Age and gender-based population norms were used to obtain $Z$ scores and percentiles for each measurement. Two-tailed $t$-tests were used to compare the two groups. The CCD group performed significantly worse in all five domains of frailty compared to healthy controls. Slowness: 6-min walk test with $Z$ score $-3.9 \pm 1.3$ vs $-1.4 \pm 1.3, p<0.001$; weakness: handgrip strength percentile $18.9 \pm 20.9$ vs $57.9 \pm 26.0$, $p<0.001$; exhaustion: multidimensional fatigue scale percentile $63.7 \pm 13.5$ vs $83.3 \pm 14.4, p<0.001$; body composition: height percentile $43.4 \pm 29.5$ vs $71.4 \pm 25.2, p<0.001$, weight percentile $46.0 \pm 36.0$ vs $70.9 \pm 24.3, p=0.006$, BMI percentile $48.4 \pm 35.5$ vs $66.9 \pm 24.2, p=0.04$, triceps skinfold thickness $41.0 \pm 24.0$ vs $54.4 \pm 22.1, p=0.04$; physical activity: pediatric activity questionnaire score $2 \pm 0.6$ vs $2.7 \pm 0.6, p<0.001$. The domains of frailty can be quantified in children using developmentally appropriate methods. CCD differ significantly from controls in all five domains, supporting the concept of quantifying the domains of frailty. Larger longitudinal studies are needed to study frailty in CCD and examine if it predicts adverse health outcomes.

Clinical Trial Registration: The ClinicalTrials.gov identification number is NCT02999438. https://clinicaltrials.gov/ct2/ show/NCT02999438.
\end{abstract}

Keywords Frailty $\cdot$ Children with heart disease $\cdot$ Fontan $\cdot$ Heart failure $\cdot$ Pulmonary hypertension $\cdot$ Congenital heart disease $\cdot$ Cardiomyopathy $\cdot$ Quality and outcomes

\begin{tabular}{lll} 
& $\begin{array}{l}\text { Abbreviations } \\
\text { CCD }\end{array}$ & Children and adolescents \\
& NYHA & $\begin{array}{l}\text { CMI } \\
\text { with cardiac disease } \\
\text { New York Heart Association } \\
\text { Body mass index }\end{array}$ \\
\hline $\begin{array}{l}\text { Chaitanya Panchangam } \\
\text { panchangams @ health.missouri.edu }\end{array}$ & $\begin{array}{l}\text { PedsQLTM } \\
\text { Fultidimensional }\end{array}$ \\
$1 \quad \begin{array}{l}\text { Fepartment of Child Health, University of Missouri Health } \\
\text { Care, Columbia, MO, USA }\end{array}$ & & $\begin{array}{l}\text { Pediatric Quality of Life } \\
\text { Inventory Multidimensional }\end{array}$ \\
$2 \quad \begin{array}{l}\text { The Ward Family Heart Center, Children's Mercy Hospital, } \\
\text { Kansas City, MO, USA }\end{array}$ & PAQ-C, PAQ-A & $\begin{array}{l}\text { Fatigue scale } \\
\text { Pediatric activity ques- } \\
\text { tionnaire for children and } \\
\text { adolescents }\end{array}$ \\
$3 \quad \begin{array}{l}\text { UMKC School of Medicine, Kansas City, MO, USA } \\
\text { University of Missouri-Columbia, 500 N Keene St, Suite }\end{array}$ & &
\end{tabular}


MAQ-C, MAQ-A

6MWT

Modifiable activity questionnaire for children and adolescents

6-Min walk test

\section{Introduction}

The frailty phenotype was described by the Cardiovascular Health Study Collaborative Research Group in older adults as a complex syndrome resulting from cumulative declines across multiple physiologic systems and leading to decreased resistance to stressors [1]. Fried et al. quantified frailty as a score based upon measurements in five domains: (1) slowness, (2) weakness, (3) self-reported exhaustion, (4) shrinkage (body composition) and (5) low physical activity. In the elderly, the frailty score has been validated as an objective assessment of overall health in chronic disease states; higher frailty scores have been associated with adverse health outcomes [1] and mortality [2], including peri-procedural mortality [3, 4]. Recent studies have suggested that frailty as a physiological phenotype may exist beyond the geriatric population. A multi-institutional study in young adult survivors of childhood cancer demonstrated that the prevalence of frailty in this population is $7.8 \%$; with higher frailty scores associated with an increased risk of morbidity and mortality [5]. A recent multicenter study compared frailty measures in children with compensated chronic liver disease to those with end-stage liver disease and found this tool to be useful in identifying the sickest individuals [6]. However, frailty has not been studied in children and adolescents with cardiac disease (CCD).

Advances in management have significantly improved the long-term survival of CCD such as heart failure, pulmonary hypertension and single ventricle disease with Fontan physiology; however, these patients continue to experience significant morbidities, including exercise intolerance [7, 8], neurocognitive delays [9], frequent hospitalizations [10] and lower quality of life [11-13]. Although serial tests such as cardiac imaging, exercise testing, and laboratory markers are frequently used as surrogate measures to monitor disease progression, there currently exists no clinical measure that can quantify the overall health status of the CCD patient and predict the risk for adverse health outcomes.

The aim of this prospective study was to evaluate the five domains of frailty in CCD and compare them to age and sex matched healthy controls. We hypothesized that: (1) the domains of frailty as described by Fried et al. can be adapted for measurement in children and adolescents using developmentally appropriate methods; and (2) CCD would perform worse than age and gender matched healthy controls across these domains.

\section{Methods}

\section{Study Design and Recruitment}

We prospectively recruited children and adolescents aged 8-17.5 years with and without CCD for this age and gender matched, case-control study. We included participants in the CCD group $(n=34)$ if they had one or more of three cardiac conditions: Single ventricle physiology with Fontan surgery, heart failure, or pulmonary arterial hypertension requiring pharmacotherapy. All patients with heart failure were classified as AHA stage B or C and were asymptomatic at the time of enrollment. We excluded participants who were wheelchair bound, tracheostomy and/ or ventilator-dependent, or had significant physical limitations that could affect their ability to complete testing. Participants who were NYHA class IV, heart failure post heart transplantation within the past 1 year or Fontan surgery within the past 6 months were also excluded. Control participants $(n=22)$, with no known chronic medical conditions, were age and sex matched to the participants in the CCD group. We excluded controls who took any prescription medications in the past 30 days. Participants were recruited by posting flyers in the cardiology clinic at our hospital and through the hospital's internal electronic newsletter. Detailed inclusion and exclusion criteria are shown in Table 1. The study protocol was approved by the Children's Mercy Hospital Institutional Review Board-16060468. Written informed consent and assent was obtained from parents and children prior to participation in any research-related data collection.

\section{Frailty Domain Measurements}

Considering the assessments used to measure the frailty domains in the Cardiovascular Health Study were developed for a geriatric sample, we modified the methodology for a sample of children and adolescents. Table 2 lists the frailty domains as described in the Cardiovascular Health Study [1] and the developmentally appropriate measurements that we obtained for each domain in our study population. Multiple measures were obtained for the domains of shrinkage/body composition and physical activity in order to determine which method was the easiest to collect (for dissemination of the frailty paradigm in clinical settings) while accurately capturing the domain's construct.

In the original Frailty paper by Fried and colleagues, slowness was measured with a $15 \mathrm{ft}$. walk test on all participants. The researchers used population data to define slowness as the slowest $20 \%$ of the population [1]. Unlike the adult population, the $15 \mathrm{ft}$. walk test does not have 
Table 1 Inclusion and exclusion criteria for the CCD group

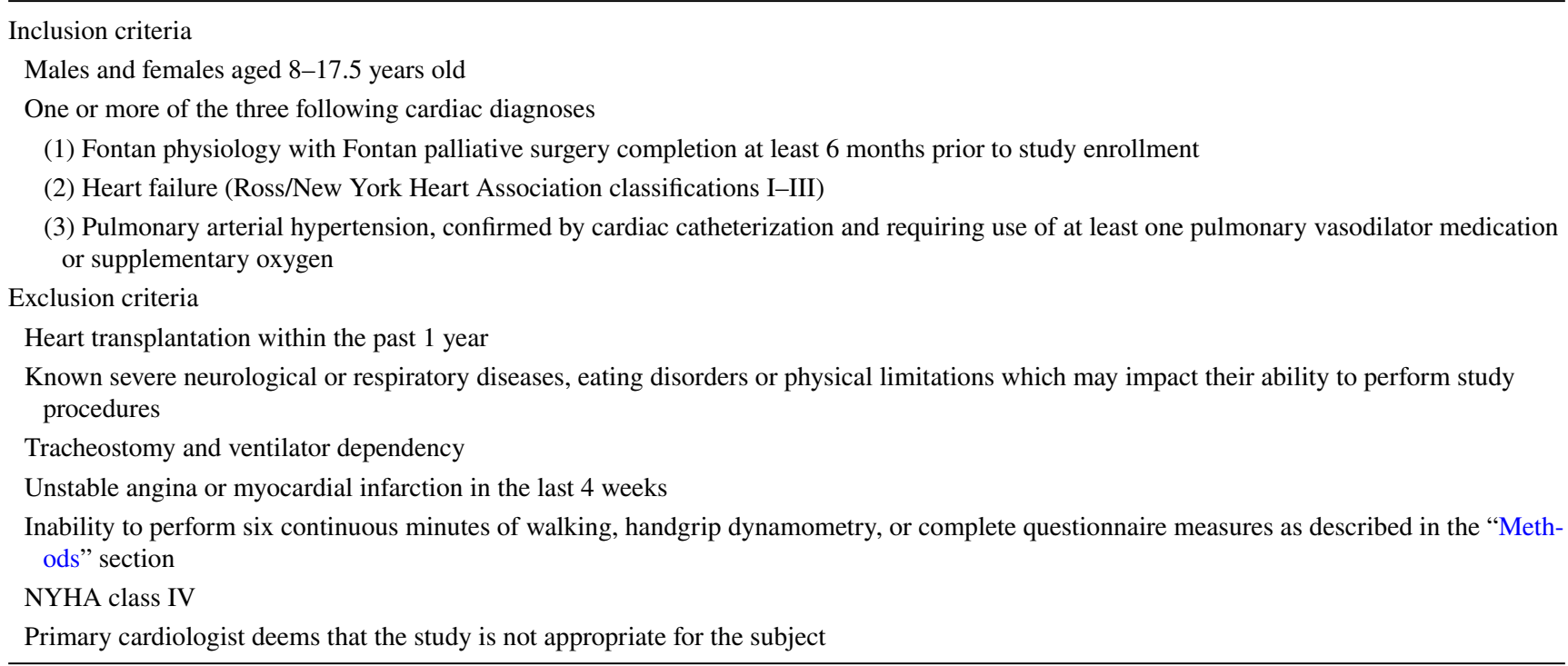

Table 2 Frailty domains and measures

\begin{tabular}{lll}
\hline Frailty domain & Measures used for adults ${ }^{\mathrm{a}}$ & Measures used for pediatrics \\
\hline (1) Slowness & $15 \mathrm{ft}$. walk test & 6-min walk test \\
(2) Weakness & Handgrip strength & Handgrip strength \\
(3) Exhaustion & CES depression scale & PedsQL Multidimensional Fatigue scale \\
(4) Shrinkage/body composition & Weight loss (over time) & Triceps skinfold thickness, height, weight, \\
& & BMI, MUAC \\
(5) Diminished physical activity & Energy expenditure estimated with physical activ- & Accelerometer, PAQ-C and PAQ-A, MAQ \\
& ity recall questionnaire & \\
\hline
\end{tabular}

$C E S$ Centers for Epidemiological Studies, $P e d s Q L$ pediatric quality of life inventory, $B M I$ body mass index, $M U A C$ mid-upper arm circumference, $P A Q$ physical activity questionnaire for children (C) or adolescents (A), MAQ modifiable activity questionnaire

${ }^{\mathrm{a}}$ Fried et al. [1]

published normative values in children and adolescents. Hence, it would be difficult to compare the results of this test between an 8 year old and a 15 year old who have markedly different stride lengths. Similar to other studies measuring frailty in youth [6], we elected to use the 6-min walk test as our measure of slowness, as it has published age and sex-based reference values for the pediatric population [14]. We provided participants with a measuring wheel with handle adjusted for their height. We asked them to walk back and forth along a 30-m path in a low traffic hallway for six continuous minutes. They were permitted to self-regulate their walking speed without jogging or running and were allowed to stop at any time to rest or lean against a wall, but not allowed to sit unless they requested that the test be terminated. We used standard 6MWT reference values for children and adolescents [14] to generate $Z$ scores.

We measured weakness using a handheld dynamometer to quantify grip strength. After sizing the dynamometer to the size of the participant's hand, we asked participants to stand with the dynamometer in their dominant hand with their arm bent at $90^{\circ}$ and squeeze it as hard as they could for $3 \mathrm{~s}$. We recorded the highest of three consecutive readings. We used age and sex-adjusted normative values [15] to generate percentiles.

We assessed exhaustion using the PedsQL ${ }^{\text {TM }}$ Multidimensional Fatigue scale which is an 18-item questionnaire designed to measure child and parent perception of fatigue. The multidimensional fatigue scale is comprised of three subscales of six items each: (1) general fatigue; (2) sleep/ rest fatigue; and (3) cognitive fatigue. This scale has been validated in children and adolescents with diverse medical conditions [16-21].

We assessed body composition by measuring height, weight, body mass index (BMI), mid-upper arm circumference, and triceps skinfold thickness. These measurements were converted to percentiles based on reference values by age and sex [22-24]. 
We assessed physical activity with self-reported physical activity questionnaires - the pediatric activity questionnaire (PAQ-C or A, for children or adolescents, respectively) and the modifiable activity questionnaire (MAQ-A, for children and adolescents). In addition, we objectively quantified physical activity using a waist worn accelerometer. The selfadministered PAQ-C and PAQ-A provides a 7-day physical activity recall $[25,26]$. We scored each questionnaire item and calculated a composite score ranging from 1 to 5 with higher scores indicating higher levels of activity [27]. The MAQ-A is an interviewer-administered questionnaire that asks participants to report household and recreational forms of physical activity over the past year. We used this information to calculate the average number of hours per week (hr/wk) of physical activity over the past year [28, 29]. We objectively measured physical activity with an ActiGraph wGT3X-BT accelerometer (ActiGraph LLC, Pensacola, FL) worn on an elastic belt over the non-dominant hip for seven consecutive days. Three days with $\geq 10 \mathrm{~h} /$ day of wear time was required for inclusion. The device was programmed to store data at 1-min epochs. Mean accelerations per minute were analyzed using the ActiLife 6 Single software and classified using the Evenson cut-points for moderate-to-vigorous intensity physical activity, MVPA [30]. MVPA in min/day were compared to estimates of physical activity from the PAQ-C or A and the MAQ-A to determine which subjective measure of physical activity was most accurate.

\section{Demographics and Medical Record Review}

We obtained demographic data from all participants to include age, gender, residence, race, household income, school performance, missed school days and medical history including ER visits and hospitalizations in the past year. The detailed list of variables is listed in Table 3 .

\section{Statistical Analysis}

We report descriptive statistics as means \pm standard deviation for continuous variables and frequency with percentage for categorical variables. We assessed differences between cases and control groups using independent $t$-tests and ANOVA for continuous variables; and $\chi^{2}$ or Fisher's exact test for categorical variables, as appropriate based on cell size. Pearson correlation was calculated among five domains of frailty measures. Cronbach's $\alpha$ was calculated
Table 3 Demographic and medical history variables

\begin{tabular}{lc}
\hline Demographic variables (CCD and control groups) & $\begin{array}{c}\text { Additional medical history } \\
\text { (CCD group only) }\end{array}$ \\
\hline Subject variables & $\begin{array}{c}\text { Subject variables } \\
\text { Cardiac diagnosis }\end{array}$ \\
Race and ethnicity & $\begin{array}{c}\text { Heart failure classifica- } \\
\text { tion }\end{array}$ \\
Grades in school (above/below/average) & \\
Failed/repeated grades & \\
Individual education plan or 504 plan & \\
Presence of primary care physician & \\
Other specialty care physicians and health care specialists & \\
Number of medications & \\
Past 12 months & \\
School days missed due to illness & \\
Emergency room visits & \\
Hospitalizations & \\
Intensive care unit admissions & \\
Days in intensive care unit & \\
Parent/family variables & \\
Residence (rural/urban/suburban) & \\
Primary caregiver of child & \\
Marital status of caregiver & \\
Individuals who live in the household & \\
Education of caregiver & \\
Employment of caregiver & \\
Annual household income & \\
Home status (rent/own) & \\
Insurance status & \\
\hline
\end{tabular}


to measure reliability of measures within a domain. Posthoc comparison was done between the NYHA classes of CCD and controls and adjusted by Tukey test.

General linear modeling was used to compare sedentary, light, moderate, vigorous, and MVPA between youth with and without CCD. Pearson correlation was used to find relationships between MVPA (min/day) to PAQ score and MAQ h/day. Results are presented as median $\mathrm{min} /$ day \pm standard error.

All statistical tests were two-sided and conducted at the $\alpha=0.05$ level. Statistical analysis was done using The SAS software v 9.4 (Copyright, SAS Institute, Inc. SAS and all other SAS Institute, Inc. product or service names are registered trademarks or trademarks of SAS Institute, Inc., Cary, NC, USA) and R (R Core Team (2015). R: a language and environment for statistical computing. $R$
Foundation for Statistical Computing, Vienna, Austria. https://www.R-project.org/).

\section{Results}

We recruited 56 participants-34 CCD and 22 controls. The demographic and clinical characteristics of the participants are presented in Table 4. Of the 34 CCD participants, there were 24 that were status post Fontan palliation, 9 with heart failure (including 3 patients with failing Fontan physiology, which was defined as having plastic bronchitis or protein-losing enteropathy) and 4 with pulmonary hypertension. Sixteen of the CCD group were NYHA class I, 15 were NYHA class II and 3 were NYHA class III, while all the controls were in NYHA class I. The CCD group were mostly from lower or middle-income
Table 4 Comparison of demographic and descriptive data between CCD and controls

\begin{tabular}{|c|c|c|c|}
\hline & $\begin{array}{l}\operatorname{CCD}(n=34) \\
n(\%)\end{array}$ & $\begin{array}{l}\text { Controls }(n=22) \\
n(\%)\end{array}$ & $p$-value \\
\hline Age (years) & $12.3 \pm 2.8$ & $11.9 \pm 2.3$ & 0.58 \\
\hline \multicolumn{4}{|l|}{ Sex } \\
\hline Males & $21(62)$ & $13(59)$ & \multirow[t]{2}{*}{0.84} \\
\hline Females & $13(38)$ & $9(41)$ & \\
\hline \multicolumn{4}{|l|}{ Race } \\
\hline White & $27(80)$ & $21(96)$ & \multirow[t]{2}{*}{0.09} \\
\hline Non-white & $7(20)$ & $1(4)$ & \\
\hline \multicolumn{4}{|c|}{ Household annual income } \\
\hline$<\$ 60,000$ & $12(35)$ & $4(18)$ & \multirow[t]{4}{*}{$<0.01 *$} \\
\hline$\$ 60,000-\$ 150,000$ & $18(53)$ & $7(32)$ & \\
\hline$>\$ 150,000$ & $1(3)$ & $11(50.0)$ & \\
\hline No answer & $3(9)$ & $0(0.0)$ & \\
\hline \multicolumn{4}{|l|}{ NYHA class } \\
\hline I & $16(47)$ & & \\
\hline II & $15(44)$ & & \\
\hline III & $3(9)$ & & \\
\hline \multicolumn{4}{|c|}{ Parent-reported academic performance } \\
\hline Above average & $6(18)$ & $14(64)$ & \multirow[t]{3}{*}{$<0.01^{*}$} \\
\hline Average & $22(65)$ & $8(36)$ & \\
\hline Below average & $6(18)$ & $0(0)$ & \\
\hline \multicolumn{4}{|l|}{ IEP or Plan 504} \\
\hline No & $12(35)$ & $21(96)$ & \multirow[t]{3}{*}{$<0.01^{*}$} \\
\hline Yes & $14(41)$ & $1(4)$ & \\
\hline Unknown & $8(24)$ & $0(0)$ & \\
\hline \multicolumn{4}{|c|}{ School days missed in the past year due to illness } \\
\hline $0-5$ & $20(59)$ & $21(95.5)$ & \multirow[t]{4}{*}{$0.025^{*}$} \\
\hline $6-10$ & $8(23)$ & $1(4.5)$ & \\
\hline $11-15$ & $1(3)$ & $0(0.0)$ & \\
\hline$>15$ & $5(15)$ & $0(0.0)$ & \\
\hline
\end{tabular}

Significant differences are denoted with *

NYHA New York Heart Association, IEP school-based individualized education plan 
families, while the controls were mostly from middle or higher income families. The CCD group were more likely to have school absenteeism from illnesses, with average or below average school performance reported by the parent, and more frequently needing IEP or Plan 504 at school.

\section{Slowness}

The 6MWT $Z$ scores were significantly lower for the CCD group as compared with controls $(Z$ score $-3.9 \pm 1.3$ vs $-1.4 \pm 1.3, p<0.001$, Table 5). Interestingly, the mean $Z$ score for controls was also lower than expected at $-1.4 \pm 1.3$. In the CCD group, 23 of the $34(68 \%)$ participants had 6MWT $Z$ scores below $-3 ; 10$ (29\% of the CCD) had 6MWT $Z$ score below - 5. In comparison, 5 (23\%) of the controls had $Z$ score below -2 .

\section{Weakness}

The CCD group had significantly lower handgrip strength as compared to controls (Table 5). 21 (62\%) of the CCD group had handgrip strength below the 25 th percentile. In comparison, nearly $64 \%$ of the controls had handgrip strength above the 50 th percentile.

\section{Exhaustion}

The maximum score on the PedsQL Multidimensional Fatigue scale is 100 , with higher scores indicating less perceived fatigue. The CCD group had significantly lower scores on both the child $(58.1 \pm 22.4$ vs $83.3 \pm 14.4$ for controls) and parent proxy $(63.1 \pm 19.5$ vs $93.1 \pm 5.4$ for controls) versions of this scale. Table 5 shows the comparison between the child multidimensional fatigue scale between CCD and controls. Within the CCD group, $62 \%$ scored less than 70 on the child form, while only 3 of the controls (14\%) scored less than 70 .

\section{Body Composition}

The CCD group had statistically significant differences in height, weight, BMI and triceps skinfold thickness as compared with the controls with lower values in CCD. The mean values for height percentile were $43.4 \pm 29.5$ for CCD as compared to $71.4 \pm 25.2$ for controls, $p<0.01$; weight percentile $46.0 \pm 36.0$ for CCD and $70.9 \pm 24.3$ for controls, $p<0.01$, BMI percentile $48.4 \pm 35.5$ for CCD and $66.9 \pm 24.2$ for controls, $p=0.04$ and triceps skinfold thickness percentile $41.0 \pm 24.0$ for CCD and $54.4 \pm 22.1$ for controls, $p=0.04$. There was no significant difference in mid-upper arm circumference between the two groups with mean percentile values of $40.1 \pm 25.8$ for CCD and $49.8 \pm 27.7$ for controls, $p=0.19$. Triceps skinfold thickness was accepted as the most appropriate measure for the body composition domain due of the ease of collection and the fact that unlike other anthropometric measurements, it is less affected by other factors such as genetic/chromosomal anomalies (Table 5).

\section{Physical Activity}

The CCD group were significantly less physically active than the controls, with lower scores for the PAQ $(2.0 \pm 0.6$ for $\mathrm{CCD}$ and $2.7 \pm 0.6$ for controls, $p<0.01$ with lower score representing less physical activity) and lower past year hr/ wk of activity from the MAQ $(7.6 \pm 6.3 \mathrm{hr} / \mathrm{wk}$ for CCD and $11.3 \pm 6.1 \mathrm{hr} / \mathrm{wk}$ for controls, $p=0.03$ ). The data from the accelerometer supported the PAQ and MAQ outcomes by demonstrating that the CCD group had less min/day of moderate intensity physical activity (CCD: $18.8 \pm 3.4 \mathrm{~min} /$ day; Control: $36.1 \pm 4.1 \mathrm{~min} /$ day, $p<0.01$ ), less vigorous intensity physical activity (CCD: $4.4 \pm 1.2 \mathrm{~min} /$ day; Control: $9.9 \pm 1.5 \mathrm{~min} /$ day; $p<0.01$ ) and MVPA (CCD: $22.2 \pm 3.4 \mathrm{~min} /$ day; Control: $46 \pm 5.2 \mathrm{~min} /$ day, $p<0.01$ ). Interestingly, there were no between group differences for sedentary time (CCD: $701.8 \pm 15.1 \mathrm{~min} /$ day; Control: $702 \pm 18.4 ; p=0.07$ ) or light intensity physical activity (CCD: $357.9 \pm 12.6 \mathrm{~min} /$ day; Control: $335 \pm 15.5$;

Table 5 Comparison of frailty domains and measures between CCD and controls

\begin{tabular}{|c|c|c|c|c|}
\hline Frailty domain & Accepted measure & $\operatorname{CCD}(n=34)$ & Controls $(n=22)$ & $p$-value \\
\hline (1) Slowness & 6MWT ( $Z$ score) & $-3.9 \pm 1.3$ & $-1.4 \pm 1.3$ & $<0.01 *$ \\
\hline (2) Weakness & Dominant handgrip strength (percentile) & $18.9 \pm 20.9$ & $57.9 \pm 26.0$ & $<0.01 *$ \\
\hline (3) Exhaustion & $\begin{array}{l}\text { PedsQL-Child Multidimensional Fatigue scale } \\
\text { (score) }\end{array}$ & $58.1 \pm 22.4$ & $83.3 \pm 14.4$ & $<0.01^{*}$ \\
\hline (4) Shrinkage/body composition & Triceps skinfold thickness (percentile) & $41.0 \pm 24.0$ & $54.4 \pm 22.1$ & $0.04^{*}$ \\
\hline (5) Diminished physical activity & PAQ-C/A (score) & $2.0 \pm 0.6$ & $2.7 \pm 0.6$ & $<0.01 *$ \\
\hline
\end{tabular}

Significant differences are denoted with *

6MWT 6-min walk test, $P e d s Q L$ pediatric quality of life inventory, $P A Q$ physical activity questionnaire for Children (C) or Adolescents (A) 
$p=0.867)$. Using the objectively measured MVPA as a reference we found the PAQ was a better subjective measure of habitual physical activity than the MAQ (PAQ: $R^{2}=0.48$, $p=0.006$; MAQ: $R^{2}=0.015, p=0.933$, Table 5). One participant from the CCD group was excluded from the accelerometer data analysis due to inadequate wear time.

\section{NYHA Class and Frailty Domains}

Due to the uneven sample sizes within the CCD group for each NYHA class, those classified as NYHA class II or III were combined into a single group. Of the 34 participants in the CCD group, 16 (47\%) were in NYHA class I, while 18 participants $(53 \%)$ were in NYHA class II or III. Figure 1a-e compares each frailty domain between the CCD group dichotomized by NYHA class and controls. Both CCD groups (NYHA class I and NYHA class II/III) scored
A

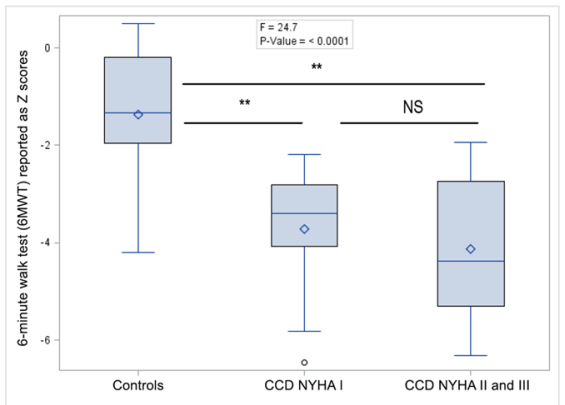

D

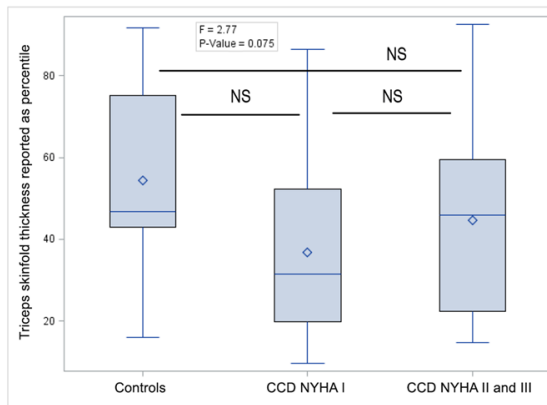

B

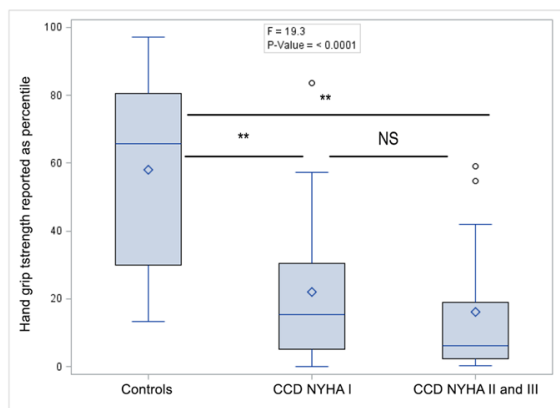

E

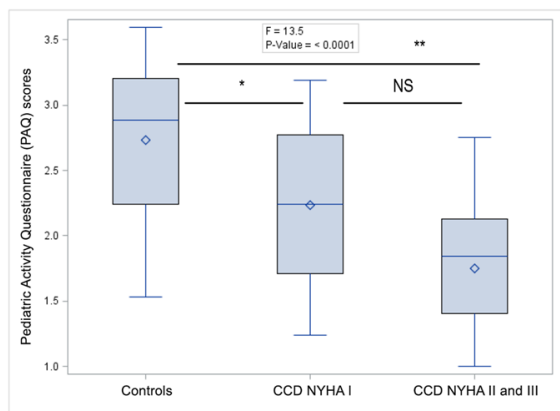

C

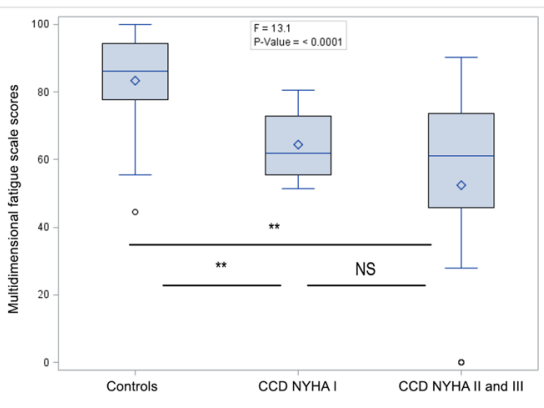

Fig. 1 Frailty domains by group with CCD group categorized by NYHA class. (A): Slowness - 6 minute walk test (6MWT) z-score; (B): Weakness - Hand grip strength percentile; (C): Exhaustion Multidimensional Fatigue scale score; (D): Shrinkage/Body composi- tion - Triceps skinfold thickness percentile; (E): Diminished physical activity - Pediatric activity questionnaire (PAQ) score. NYHA - New York Heart Association heart failure classification. NS $=$ Not significant, $*=p<0.05, * *=p<0.01$

Table 6 Correlations between frailty domains

6MWT Handgrip strength $\quad$ PedsQL Multidimensional $\quad$ Triceps skinfold thickness
Fatigue scale

6MWT

Handgrip strength

PedsQL Multidimensional

Fatigue scale

Triceps skinfold thickness

PAQ-C/A

$$
\begin{array}{ll}
r=0.7, p<0.01^{*} & \\
r=0.46, p=0.01^{*} & r=0.39, p<0.01^{*} \\
r=0.27, p=0.04^{*} & r=0.39, p<0.01^{*} \\
r=0.49, p<0.01^{*} & r=0.45, p<0.01^{*}
\end{array}
$$$$
r=0.07, p=0.61
$$$$
r=0.32, p=0.02 *
$$$$
r=-0.05, p=0.74
$$

Significant differences are denoted with *

6MWT 6-min walk test, $P A Q$ physical activity questionnaire for Children (C) or Adolescents (A) 
significantly lower than controls for: 6MWT, handgrip strength, PedsQL Multidimensional Fatigue scale, and PAQ, but not triceps skinfold thickness. Within the CCD group, there were no significant differences between NYHA class groups for any frailty domain.

\section{Correlation Between the Frailty Measures Within and Between Domains}

The Cronbach's $\alpha$ value between various anthropometric measures was 0.9 , suggesting strong correlation. The Cronbach's $\alpha$ value for child filled and parent proxy versions of the PedsQL Multidimensional Fatigue scale was 0.80, while that for the PAQ and MAQ was 0.7. Table 6 lists the correlation (Pearson's correlation coefficient) between the different domains of frailty. There were positive correlations between most of the frailty domains with Pearson correlation coefficients ranging from 0.27 to 0.7 . Body composition measured with triceps skinfold thickness did not significantly correlate with exhaustion measured with PedsQL Multidimensional Fatigue scale or physical activity measured with PAQ-C/A, but it did correlate with handgrip strength and 6MWT. The significant correlations indicate that the domains complement each other, but are not identical, avoiding too much overlap and redundancy.

\section{Discussion}

To our knowledge, this is the first study that attempts to examine the phenotype of frailty in CCD. We found that it is feasible to assess and measure the domains of frailty in children, by adapting the original measures described in geriatric population to those that are developmentally appropriate for the pediatric population. Furthermore, we found that the CCD participants performed significantly worse than age and gender matched healthy controls in all five domains of frailty.

We chose three specific forms of CCD-Fontan physiology, heart failure, and pulmonary hypertension because these conditions are associated with significant morbidity, mortality and a lifelong burden on health and economics [31-33]. With improvements in medical management, the survival of CCD has improved considerably $[34,35]$ and the focus is now shifting towards optimizing their quality of life [7-9, 11, 12]. At present, there is no clear consensus on parameters that can help to identify patients at highest risk of adverse health outcomes such as hospitalization or mortality. The current standard of medical care consists of periodic ambulatory clinic visits with testing including echocardiography, exercise testing, and monitoring for arrhythmia. While these tests provide useful information about cardiac function, they neither correlate with overall debility; nor do they adequately predict risk of future adverse events [36-39]. Knowing that debilitating morbidities are not limited to only specific cardiac conditions, the intention of this study was to develop a broad based, generalizable clinical measure of infirmity for children and adolescents with cardiac disease. CCD have similar potential to score poorly within each domain of frailty regardless of diagnoses, therefore we chose a heterogeneous sample of different cardiac diagnoses with known higher physical and psychosocial burden of disease.

The frailty score as originally described by Fried et al. [1] was a population-based score in the elderly that were not hospitalized or end stage, and helped identify individuals at the highest risk of mortality. A high frailty score was associated in this study with increased risk of mortality and adverse outcomes. Since the original publication, the frailty score has been extensively studied in adults and has been found to be associated with adverse outcomes in a heterogeneous array of medical conditions such as liver [40] and renal disease [41], post-operative patients [4, 42, 43] and in heart failure [44]. If such a score could be designed and validated in the CCD population, it could be immensely helpful in identifying the patients that are most at risk for deterioration, so that more aggressive medical and supportive therapy could be targeted towards them. The concept could be extended to other chronic disease states in children as well. The frailty score has the advantage of being internationally recognized [45] and widely tested by clinicians in adult literature. We thus sought to adapt the domains of frailty to the pediatric population by using age appropriate techniques that have been well studied over the years and have normal age and gender specific reference values available [14, 15, 22-24].

Lurz et al. recently published their experience in assessing frailty in children with liver disease [6]. In this multicenter study, they recruited 36 children with compensated liver disease and 35 with end-stage liver disease. They found worse frailty scores in those children with end-stage liver disease when compared to controls with compensated chronic liver disease; a frailty score of $>5$ had the best sensitivity and specificity in identifying children with end-stage liver disease. Similar to our study, the investigators used standard, developmentally appropriate and validated tools to assess the frailty domains, such as grip strength by hand dynamometer, 6MWT, triceps skinfold thickness, PedsQL 4.0 Multidimensional Fatigue scale and the modified PAQ. In our study, we used multiple measures for some of the domains as we have previously described; this is because it is yet unclear which measures could be of most value in generating a future pediatric frailty score. For example, considering subjective reports of physical activity may be skewed 
by perception and memory recall, we compared two different validated physical activity questionnaires to physical activity measured objectively via accelerometer. Similar to the study by Voss et al. [46], we found the PAQ for children or adolescents was an accurate subjective measure of physical activity in this population.

Lurz et al. assigned frailty scores for each component based on arbitrary $Z$ score cutoffs, with the maximum possible score being 10 (most frail). We chose not to create a score because the current study design did not include longitudinal follow-up for outcome data. At this initial stage, we compared our study participants to normal controls to establish feasibility and clinical relevance.

We found several similarities between our CCD group and the elderly frail population. Both reported higher levels of exhaustion and lower levels of physical activity. One of the key drivers of the frail state in the elderly is chronic undernutrition and loss of lean body mass leading to negative nitrogen balance. Our CCD cohort had lower anthropometric measures and triceps fold thickness compared to controls, though mid arm circumference was similar. A recent study done in patients with Fontan physiology showed that lower height percentiles were associated with worse functional outcomes [47]. However, since congenital heart disease could be associated with genetic short stature, assessment of height may be a confounding variable. Measurement of triceps skinfold thickness should be considered in assessing $\mathrm{CCD}$ as it is less affected by other factors such as genetic or chromosomal anomalies. It seems unlikely that children with cardiac disease would lose weight unless severely ill and incapacitated. Therefore, overall somatic growth, or a serial decrease in percentile measurements may be more relevant than weight loss in this population.

In our study, we noted a significant difference in physical performance even between controls and CCD that were functioning at NYHA class I. Given the chronic nature of underlying heart disease and slow progression, it is conceivable that CCD have adapted to it and are unaware of the true extent of their diminished reserves. A study in adults with congenital heart disease (mean age $33 \pm 13$ years) demonstrated markedly impaired peak oxygen consumption even in participants in NYHA class I as compared to healthy controls [48]. The authors concluded that NYHA class underestimated the true degree of exercise limitation. Lurz et al. noted that the frailty scores in children with chronic liver disease did not correlate with physicians' subjective assessments or commonly used objective scores to assess extent of liver disease [6]. Hence, NYHA classification and physicians' subjective assessments may have limitations that the frailty score, as an objectively measured score may be able to overcome. We did not find a difference within the CCD group for the different NYHA classes; this is likely because the study was underpowered to detect differences within subgroups.

Finally, recent studies have examined the reversibility of frailty as a detrimental physiologic state. Pin $\mathrm{Ng}$ et al. looked at the effect of nutritional, physical rehabilitation and cognitive training in frail adults and found that these interventions could improve the frailty score over 12 months; however, there was no difference in secondary outcomes such as hospitalizations or mortality, likely due to the study being underpowered to assess those outcomes [49]. Monteserin et al. in a larger study of 620 participants, found that a higher percentage of participants reversed their frailty risk after receiving interventions aimed at health promotion as compared to controls receiving usual care [50]. Studies in pediatric Fontan patients have shown improvement in cardiac output and quality of life following endurance training, suggesting potential benefits of interventions even in children [51, 52]. It is conceivable that identification of the frailty phenotype in children could be beneficial in identifying those individuals at risk and designing specific interventions to potentially reverse their risk for adverse health outcomes. The frailty measures do take time to administer, especially in a busy clinic practice.

While this study adds important knowledge to the literature, it does have some limitations. It is a single-site study with a small sample drawn from a limited geographic area. The controls were selected mostly from children of employees, potentially leading to selection bias. Because of the small sample size and lack of longitudinal follow-up, this study is a first step towards the creation of a frailty score in CCD. The performance of our healthy controls on the $6 \mathrm{MWT}$ was below the published population norms. This could potentially be from the methodology used, wherein we had participants walk back and forth across a small hallway and they may have lost time in turning around thereby affecting the total distance covered. Although we cannot be entirely sure, it is also possible that the control participants performed at a level lower than expected for the 6MWT due to lack of motivation to complete the test to the best of their ability despite encouragement. While none of the Fontan participants had activity restrictions imposed by their cardiologist, it is not possible to exclude self-restriction by the patient or family due to anxiety surrounding their cardiac diagnosis, which could have affected the scores on the activity questionnaires and accelerometer.

In summary, the domains of frailty, as described in the elderly, can be assessed in the pediatric population using developmentally appropriate methods. CCD perform worse across all the domains of frailty as compared to than age and gender matched healthy controls, suggesting the relevance of frailty as a phenotype in this population. Additional research is warranted to delineate thresholds to define the phenotype 
of frailty by correlating frailty measures with longitudinal health outcomes.

Acknowledgements Diana Connelly (Research Coordinator), Dai Hongying $\mathrm{PhD}$ (Bio-statistician).

Author Contributions CP: Concept/Design, Data analysis/interpretation, Drafting article, Approval of article, Statistics, Data collection. DW: Concept/Design, Data analysis/interpretation, Critical revision of article, Approval of article, Statistics, Data collection. SG: Concept/ Design, Approval of article. BB: Concept/Design, Critical revision of article, Approval of article. LM-W: Concept/Design, Approval of article. JG-T: Concept/Design, Approval of article. KJR: Concept/Design, Statistics, Approval of article. GS: Concept/Design, Critical revision of article, Approval of article. AP: Concept/Design, Critical revision of article, Approval of article.

Funding The study was funded by The Ward Family Heart Center at Children's Mercy Hospital. The ClinicalTrials.gov Identification Number is NCT02999438.

\section{Compliance with Ethical Standards}

Conflict of interest The authors declare that they have no conflict of interest.

Ethical Approval All procedures performed in studies involving human participants were in accordance with the Ethical Standards of the Institutional and/or National Research Committee (Children's Mercy Hospital Institutional Review Board-16060468) and with the 1964 Helsinki Declaration and its later amendments or comparable ethical standards.

\section{References}

1. Fried LP, Tangen CM, Walston J, Newman AB, Hirsch C, Gottdiener J, Seeman T, Tracy R, Kop WJ, Burke G, McBurnie MA, CHSCR Group (2001) Frailty in older adults: evidence for a phenotype. J Gerontol A 56:M146-M156

2. Shamliyan T, Talley KMC, Ramakrishnan R, Kane RL (2013) Association of frailty with survival: a systematic literature review. Ageing Res Rev 12:719-736

3. Murali-Krishnan R, Iqbal J, Rowe R, Hatem E, Parviz Y, Richardson J, Sultan A, Gunn J (2015) Impact of frailty on outcomes after percutaneous coronary intervention: a prospective cohort study. Open Heart 2:e000294

4. Lee DH, Buth KJ, Martin B-J, Yip AM, Hirsch GM (2010) Frail patients are at increased risk for mortality and prolonged institutional care after cardiac surgery. Circulation 121:973-978

5. Ness KK, Krull KR, Jones KE, Mulrooney DA, Armstrong GT, Green DM, Chemaitilly W, Smith WA, Wilson CL, Sklar CA, Shelton K, Srivastava DK, Ali S, Robison LL, Hudson MM (2013) Physiologic frailty as a sign of accelerated aging among adult survivors of childhood cancer: a report from the St Jude Lifetime Cohort Study. J Clin Oncol 31:4496-4503

6. Lurz E, Quammie C, Englesbe M, Alonso EM, Lin HC, Hsu EK, Furuya KN, Gupta NA, Venkat VL, Daniel JF, Leonis MA, Miloh T, Telega GW, Yap J, Menendez J, Book LS, Himes RW, Sundaram SS, Parekh R, Sonnenday C, Bucuvalas J, Ng VL, Kamath BM (2018) Frailty in children with liver disease: a prospective multicenter study. J Pediatr 194:109-115.e104
7. Paridon SM, Mitchell PD, Colan SD, Williams RV, Blaufox A, Li JS, Margossian R, Mital S, Russell J, Rhodes J, PHN Investigators (2008) A cross-sectional study of exercise performance during the first 2 decades of life after the Fontan operation. J Am Coll Cardiol 52:99-107

8. Fraisse A, Jais X, Schleich J-M, di Filippo S, Maragnès P, Beghetti M, Gressin V, Voisin M, Dauphin C, Clerson P, Godart F, Bonnet D (2010) Characteristics and prospective 2-year follow-up of children with pulmonary arterial hypertension in France. Arch Cardiovasc Dis 103:66-74

9. 9Sugimoto A, Ota N, Ibuki K, Miyakoshi C, Murata M, Tosaka Y, Yamazaki T, Sakamoto K (2013) Risk factors for adverse neurocognitive outcomes in school-aged patients after the Fontan operation. Eur J Cardiothorac Surg Off J Eur Assoc Cardiothorac Surg 44:454-461; discussion 461

10. Nandi D, Rossano JW (2015) Epidemiology and cost of heart failure in children. Cardiol Young 25:1460-1468

11. Shafazand S, Goldstein MK, Doyle RL, Hlatky MA, Gould MK (2004) Health-related quality of life in patients with pulmonary arterial hypertension. Chest 126:1452-1459

12. Uzark K, Zak V, Shrader P, McCrindle BW, Radojewski E, Varni JW, Daniels K, Handisides J, Hill KD, Lambert LM, Margossian R, Pemberton VL, Lai WW, Atz AM, PHN Investigators (2016) Assessment of quality of life in young patients with single ventricle after the Fontan operation. J Pediatr 170:166-172.e161

13. den Boer SL, Baart SJ, van der Meulen MH, van Iperen GG, Backx AP, Ten Harkel AD, Rammeloo LA, du Marchie Sarvaas GJ, Tanke RB, Helbing WA, Utens EM, Dalinghaus M (2017) Parent reports of health-related quality of life and heart failure severity score independently predict outcome in children with dilated cardiomyopathy. Cardiol Young 27(6):1-9

14. Geiger R, Strasak A, Treml B, Gasser K, Kleinsasser A, Fischer V, Geiger H, Loeckinger A, Stein JI (2007) Six-minute walk test in children and adolescents. J Pediatr 150(395-399):399.e391-392

15. Bohannon RW, Wang YC, Bubela D, Gershon RC (2017) Handgrip strength: a population-based study of norms and age trajectories for 3- to 17-year-olds. Pediatr Phys Ther 29:118-123

16. Panepinto JA, Torres S, Bendo CB, McCavit TL, Dinu B, Sherman-Bien S, Bemrich-Stolz C, Varni JW (2014) PedsQL ${ }^{\mathrm{TM}}$ Multidimensional Fatigue Scale in sickle cell disease: feasibility, reliability, and validity. Pediatr Blood Cancer 61:171-177

17. Varni JW, Burwinkle TM, Katz ER, Meeske K, Dickinson P (2002) The PedsQL in pediatric cancer: reliability and validity of the Pediatric Quality of Life Inventory Generic Core Scales, Multidimensional Fatigue Scale, and Cancer Module. Cancer 94:2090-2106

18. Varni JW, Burwinkle TM, Szer IS (2004) The PedsQL Multidimensional Fatigue Scale in pediatric rheumatology: reliability and validity. J Rheumatol 31:2494-2500

19. Varni JW, Limbers CA, Bryant WP, Wilson DP (2009) The PedsQL Multidimensional Fatigue Scale in type 1 diabetes: feasibility, reliability, and validity. Pediatr Diabetes 10:321-328

20. Varni JW, Limbers CA, Bryant WP, Wilson DP (2010) The PedsQL Multidimensional Fatigue scale in pediatric obesity: feasibility, reliability and validity. Int J Pediatr Obes 5:34-42

21. Kobayashi K, Okano Y, Hohashi N (2011) Reliability and validity of the PedsQL ${ }^{\text {TM }}$ Multidimensional Fatigue Scale in Japan. Qual Life Res 20:1091-1102

22. Centers of Disease Control (2011) Healthy weight: assessing your weight: BMI for children and teens. CDC, Atlanta

23. Kuczmarski RJ, Ogden CL, Grummer-Strawn LM, Flegal KM, Guo SS, Wei R, Mei Z, Curtin LR, Roche AF, Johnson CL (2000) CDC growth charts: United States. Adv Data (314):1-27

24. McDowell MA, Fryar CD, Hirsch R, Ogden CL (2005) Anthropometric reference data for children and adults: U.S. population, 1999-2002. Adv Data (361):1-5 
25. Kowalski KC, Crocker PR, Faulkner RA (1997) Validation of the physical activity questionnaire for older children. Pediatr Exerc Sci 9:174-186

26. Kowalski KC, Crocker PR, Kowalski NP (1997) Convergent validity of the physical activity questionnaire for adolescents. Pediatr Exerc Sci 9:342-352

27. Kowalski KC, Crocker PRE; Donen RM (2004) The Physical Activity Questionnaire for older children (PAQ-C) and adolescents (PAQ-A) manual. https://www.performwell.org

28. Aaron D, Kriska A, Dearwater S, Cauley J, Metz K, LaPorte R (1995) Reproducibility and validity of an epidemiologic questionnaire to assess past year physical activity in adolescence. Am J Epidemiol 142:191-201

29. Kriska AM, Knowler WC, LaPorte RE, Drash AL, Wing RR, Blair SN, Bennett PH, Kuller LH (1990) Development of questionnaire to examine relationship of physical activity and diabetes in Pima Indians. Diabetes Care 13:401-411

30. Evenson KR, Catellier DJ, Gill K, Ondrak KS, McMurray RG (2008) Calibration of two objective measures of physical activity for children. J Sports Sci 26:1557-1565

31. Hsu DT, Pearson GD (2009) Heart failure in children: Part I: history, etiology, and pathophysiology. Circ Heart Fail 2:63-70

32. Frank DB, Crystal MA, Morales DLS, Gerald K, Hanna BD, Mallory GB, Rossano JW (2015) Trends in pediatric pulmonary hypertension-related hospitalizations in the United States from 2000-2009. Pulm Circ 5:339-348

33. Faraoni D, Nasr VG, DiNardo JA (2016) Overall hospital cost estimates in children with congenital heart disease: analysis of the 2012 Kid's Inpatient Database. Pediatr Cardiol 37:37-43

34. d'Udekem Y, Iyengar AJ, Galati JC, Forsdick V, Weintraub RG, Wheaton GR, Bullock A, Justo RN, Grigg LE, Sholler GF, Hope S, Radford DJ, Gentles TL, Celermajer DS, Winlaw DS (2014) Redefining expectations of long-term survival after the Fontan procedure: twenty-five years of follow-up from the entire population of Australia and New Zealand. Circulation 130:S32-S38

35. Barst RJ, McGoon MD, Elliott CG, Foreman AJ, Miller DP, Ivy DD (2012) Survival in childhood pulmonary arterial hypertension: insights from the registry to evaluate early and long-term pulmonary arterial hypertension disease management. Circulation 125:113-122

36. 36Griffiths ER, Kaza AK, Wyler von Ballmoos MC, Loyola H, Valente AM, Blume ED, del Nido P (2009) Evaluating failing Fontans for heart transplantation: predictors of death. Ann Thorac Surg 88:558-563; discussion 554-563

37. Badagliacca R, Poscia R, Pezzuto B, Papa S, Nona A, Mancone M, Mezzapesa M, Nocioni M, Sciomer S, Valli G, Cedrone N, Fedele F, Vizza CD (2012) Pulmonary arterial dilatation in pulmonary hypertension: prevalence and prognostic relevance. Cardiology 121:76-82

38. Bandorski D, Bogossian H, Stempfl J, Seeger W, Hecker M, Ghofrani A, Hoeltgen R, Gall H (2016) Prognostic relevance of nonsustained ventricular tachycardia in patients with pulmonary hypertension. BioMed Res Int 2016:1327265

39. Stepnowska E, Lewicka E, Dabrowska-Kugacka A, DanilowiczSzymanowicz L, Zagozdzon P, Kaminski R, Lewicka-Potocka Z, Miekus P, Kozlowski D, Potocki W, Raczak G (2018) Predictors of poor outcome in patients with pulmonary arterial hypertension: a single center study. PLoS ONE 13:e0193245
40. Lai JC, Covinsky KE, Dodge JL, Boscardin WJ, Segev DL, Roberts JP, Feng S (2017) Development of a novel frailty index to predict mortality in patients with end-stage liver disease. Hepatology 66:564-574

41. Kutner NG, Zhang R (2013) Frailty in dialysis-dependent patients with end-stage renal disease. JAMA Intern Med 173:78-79

42. Runner RP, Bellamy JL, Vu CCL, Erens GA, Schenker ML, Guild GN III (2017) Modified frailty index is an effective risk assessment tool in primary total knee arthroplasty. J Arthroplast 32:S177-S182

43. McIsaac DI, Moloo H, Bryson GL, van Walraven C (2017) The association of frailty with outcomes and resource use after emergency general surgery: a population-based cohort study. Anesth Analg 124:1653-1661

44. Uchmanowicz I, Wleklik M, Gobbens RJJ (2015) Frailty syndrome and self-care ability in elderly patients with heart failure. Clin Interv Aging 10:871-877

45. Mauthner O, Claes V, Deschodt M, Jha SR, Engberg S, Macdonald PS, Newton PJ, De Geest S (2017) Handle with care: a systematic review on frailty in cardiac care and its usefulness in heart transplantation. Transplant Rev (Orlando) 31:218-224

46. Voss C, Dean PH, Gardner RF, Duncombe SL, Harris KC (2017) Validity and reliability of the Physical Activity Questionnaire for Children (PAQ-C) and Adolescents (PAQ-A) in individuals with congenital heart disease. PLoS ONE 12:e0175806

47. Cohen MS, Zak V, Atz AM, Printz BF, Pinto N, Lambert L, Pemberton V, Li JS, Margossian R, Dunbar-Masterson C, McCrindle BW (2010) Anthropometric measures after Fontan procedure: implications for suboptimal functional outcome. Am Heart J 160(1092-1098):1098.e1091

48. Diller GP, Dimopoulos K, Okonko D, Li W, Babu-Narayan SV, Broberg CS, Johansson B, Bouzas B, Mullen MJ, Poole-Wilson PA, Francis DP, Gatzoulis MA (2005) Exercise intolerance in adult congenital heart disease: comparative severity, correlates, and prognostic implication. Circulation 112:828-835

49. Ng TP, Feng L, Nyunt MS, Feng L, Niti M, Tan BY, Chan G, Khoo SA, Chan SM, Yap P, Yap KB (2015) Nutritional, physical, cognitive, and combination interventions and frailty reversal among older adults: a randomized controlled trial. Am J Med 128:1225-1236.e1221

50. Monteserin R, Brotons C, Moral I, Altimir S, San Jose A, Santaeugenia S, Sellares J, Padros J (2010) Effectiveness of a geriatric intervention in primary care: a randomized clinical trial. Fam Pract 27:239-245

51. Hedlund ER, Lundell B, Soderstrom L, Sjoberg G (2018) Can endurance training improve physical capacity and quality of life in young Fontan patients? Cardiol Young 28:438-446

52. Cordina RL, O’Meagher S, Karmali A, Rae CL, Liess C, Kemp GJ, Puranik R, Singh N, Celermajer DS (2013) Resistance training improves cardiac output, exercise capacity and tolerance to positive airway pressure in Fontan physiology. Int J Cardiol 168:780-788

Publisher's Note Springer Nature remains neutral with regard to jurisdictional claims in published maps and institutional affiliations. 